\title{
Current State and Principles of Basal Insulin Therapy in Type 2 Diabetes
}

\author{
Hernando Vargas-Uricoechea (1)
}

\begin{abstract}
Treatment with basal insulins is a fundamental part of management in many patients with type 2 diabetes mellitus. Multiple management schemes may be indicated in these individuals, for example, the use of oral antihyperglycemic agents with basal insulins (basal-supported oral therapy) or the combinations of basal insulins with glucagon-like peptide-1 receptor agonists; each of these strategies makes it easier to achieve glycemic control goals. A basic knowledge of the physiology, pharmacodynamic and pharmacokinetic aspects of the different basal insulins is essential to achieve treatment goals and compliance. This review addresses the principles of management with basal insulins.
\end{abstract}

Keywords: Diabetes; Insulin; NPH; Detemir; Glargine; Degludec

\section{Introduction}

Type 2 diabetes mellitus (T2DM) is a condition of a polygenic nature and variable penetrance, in which a series of alterations in the metabolism of macronutrients (lipids, carbohydrates, and proteins) coexist. This leads to a state of chronic hyperglycemia and a significant increase in the risk of micro- and macrovascular outcomes [1-3].

Multiple genetic, environmental, and epigenetic interactions have been described in T2DM along with various pathophysiological mechanisms, predominantly insulin resistance and the progressive decrease in insulin secretory capacity by pancreatic $\beta$ cells. This last mechanism is the one that ultimately determines the need for insulin management $[4,5]$. One of the strategies to achieve metabolic control in T2DM when management with oral antihyperglycemic drugs (OADs) and other parenteral treatments, such as glucagon-like peptide-1 receptor agonists (GLP-1RAs), is not sufficient is the use of insulin, especially basal insulins (BIs) [6].

This review describes the basic principles of management

Manuscript submitted January 13, 2022, accepted January 20, 2022

Published online January 29, 2022

Metabolic Diseases Study Group, Department of Internal Medicine, Universidad del Cauca, Popayan, Colombia.

Email: hernandovargasuricoechea@gmail.com

doi: https://doi.org/10.14740/jocmr4660 with BIs, from the most common pathophysiological aspects to the current evidence from randomized clinical trials (RCTs) with next-generation insulins.

\section{Methods}

A detailed search was carried out in the following databases: PubMed/MEDLINE, EMBASE, Scopus, BIOSIS, ClinicalTrials.gov, Web of Science, and Cochrane Library. This search was conducted for articles published from January 1 (2001) to August 31 (2021), using the terms "insulin", "NPH", "Glargine-100", "Glargine-300", "Degludec-100", "Degludec-200", "Detemir", and "type 2 diabetes". Other definitions of diabetes or other associated conditions (chronic kidney disease, elderly, intercurrent illnesses, or situations requiring temporary insulin management) were not taken into account in this review. Only RCTs that evaluated the efficacy and safety of BIs (and were exclusively in the English language) were taken into account.

\section{Normal Glucose Homeostasis}

Typically, a person is considered to be fasting when $8-12 \mathrm{~h}$ has elapsed without food intake. Metabolic changes occur after the absorption of a meal (generally after $3-5 \mathrm{~h}$ ); this state is also known as the "postabsorptive state", as opposed to the "postprandial" (or digestion in progress) state [7].

During the fasting state, the oxidation of free fatty acids (FFAs) contributes to a greater energy expenditure than the oxidation of some macronutrients (such as carbohydrates). This aspect is considered to be caused by a greater availability of lipids and carbohydrates since the concentrations of unesterified FFA at the plasma level increase in response to a lower concentration of insulin and high levels of counter-regulatory hormones (such as glucagon) [8].

After its absorption, the concentration of plasma glucose (PG) from the physiological point of view is established to be between 70 and $110 \mathrm{mg} / \mathrm{dL}$. This value remains relatively stable thanks to the regulatory effects of glucagon and insulin. Under normal conditions, of the total glucose that can potentially be used, $50 \%$ use occurs in the brain, $25 \%$ at the splanchnic level, and $25 \%$ in insulin-dependent tissues (such as muscle and adipose tissue) [9].

Likewise, in the postprandial state, an increase in both PG concentration and insulin secretion is documented. The latter 


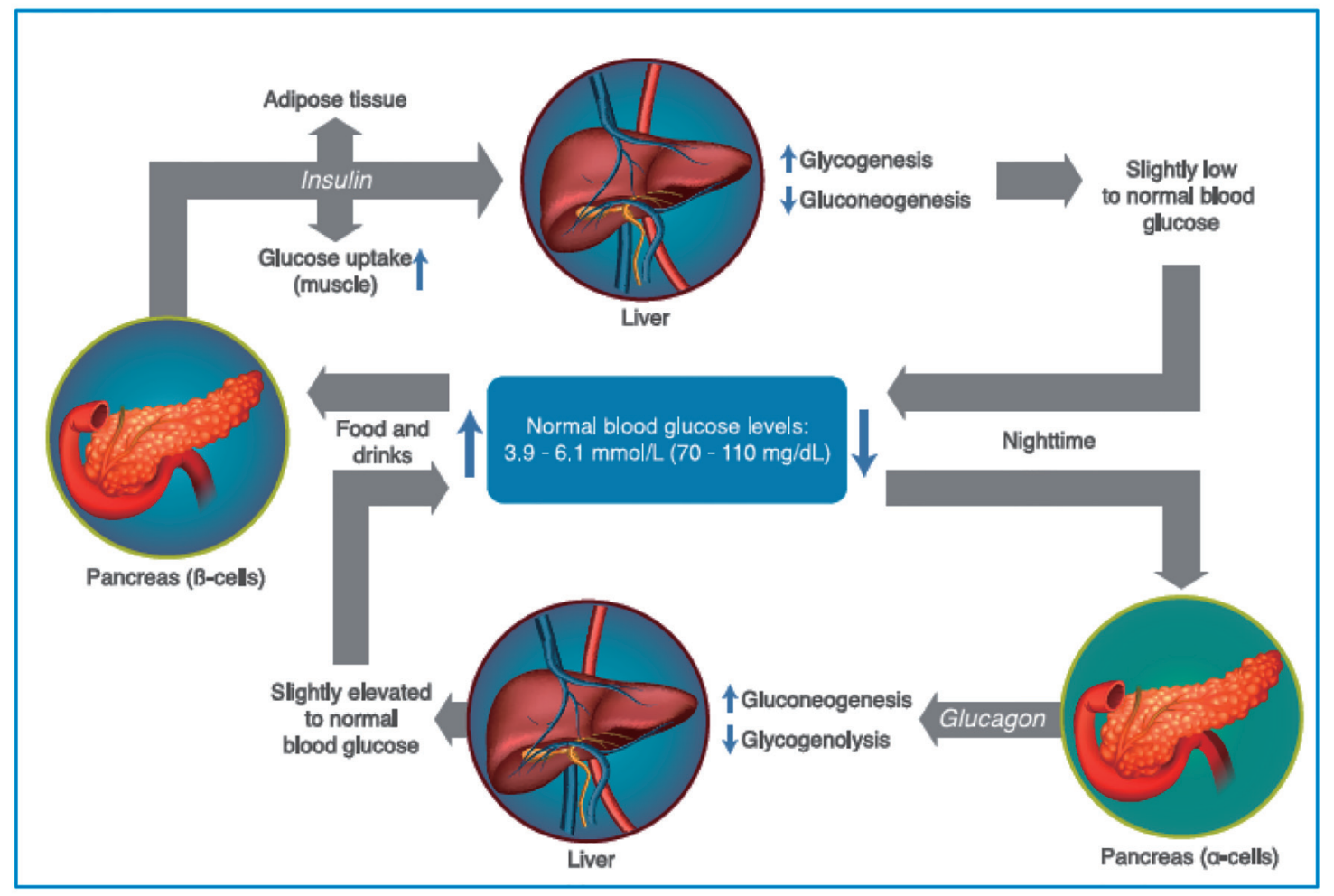

Figure 1. Maintenance of plasma glucose levels, through the regulation of insulin and glucagon. As glycemic levels drop, the pancreatic $\alpha$ cells secrete glucagon, increasing gluconeogenesis and glycogenolysis, increasing the levels of glycemia. After food intake, the levels of glycemia rise promoting insulin release (by the pancreatic $\beta$ cells) which increase the glucose uptake in the muscle and adipose tissue, in addition to promoting glycogenogenesis and reducing gluconeogenesis (see text for additional details). Source: author's elaboration.

aspect is translated into a suppression of gluconeogenesis and an increase in the rate of glucose elimination (at the hepatic and posthepatic level) (Fig. 1) [10].

\section{Normal Insulin Physiology}

Insulin is synthesized and secreted from $\beta$ cells and consists of two polypeptide chains, chain A (with 21 amino acids) and chain B (with 30 amino acids), linked by disulfide bridges [11].

Insulin synthesis depends on a precursor (preproinsulin), cleaved off and converted to proinsulin. Next, proinsulin is packaged in the Golgi apparatus (of the $\beta$ cell) to be later converted (enzymatically) into insulin and connecting peptide (Cpeptide) $[12,13]$.

In the Golgi apparatus, proinsulin enters the secretory and storage vesicles (rich in zinc and calcium $\left(\mathrm{Ca}^{2+}\right)$ ). Once inside the vesicles, hexamer structures develop from proinsulin, with two zinc atoms per proinsulin hexamer, which subsequently become the insulin hexamer (producing C-peptide as well), leaving the $\mathrm{C}$-terminal and $\mathrm{N}$-terminal free. Insulin is then synthetized and stored as a hexamer, but its active form is that of a monomeric hormone [13].

In healthy individuals, the concentration of PG fluctuates and is affected by factors such as nutritional intake, physical activity, hormone interactions, and macromolecules; however, the PG remains within a narrow range of values $(63-126 \mathrm{mg} /$ dL) [14]. In a normal physiological setting, circulating insulin levels are closely related to tissue insulin sensitivity (which is defined as the ability to remove glucose and suppress hepatic gluconeogenesis in response to insulin) $[14,15]$. The insulin secretion rate is regulated according to the concentration of $\mathrm{PG}$; this secretion increases as PG levels rise above $60 \mathrm{mg} / \mathrm{dL}$. About $50 \%$ of the total daily insulin secretion occurs during the basal periods [16].

Circulating PG is taken up by the facilitating glucose transporter isoform 2 (GLUT2) (solute carrier family 2 member 2 (SLC2A2)). When glucose enters the cell (through GLUT2), it undergoes a phosphorylation process (mediated by glucokinase), and glucose-6-phosphate is generated, which, through glycolysis, forms pyruvate. Pyruvate then enters the Krebs cycle to produce nicotinamide adenine dinucleotide and flavin adenine dinucleotide, which are oxidatively metabolized to produce adenosine triphosphate (ATP). This production induces an increase in the ATP/adenosine diphosphate ratio, which leads to the closure of potassium channels $\left(\mathrm{K}^{+}\right)$sensitive to ATP (KATP) [17, 18].

After the closing of the channels, there is a decrease in the magnitude of the $\mathrm{K}^{+}$current (outward), inducing the depolarization of the cell membrane, with the respective opening of the voltage-dependent $\mathrm{Ca}^{2+}$ channels. This cytosolic increase of the $\mathrm{Ca}^{2+}$ levels generates exocytosis of insulin granules [19]. 


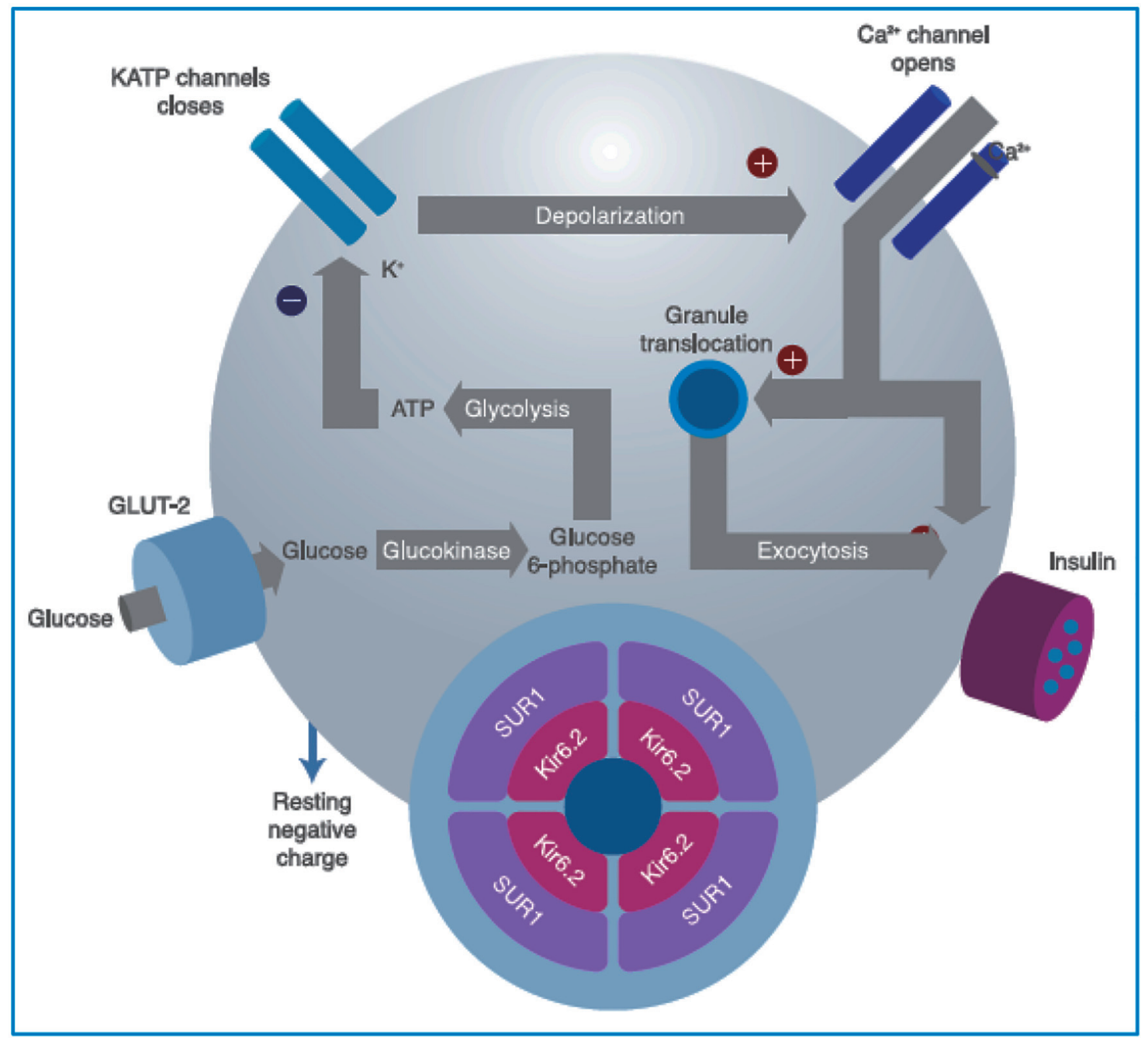

Figure 2. Intracellular mechanisms through which glucose stimulates insulin secretion. Glucose is metabolized inside the $\beta$ cell for ATP production, closing the ATP-sensitive $\mathrm{K}^{+}$channels on the cell membrane. This prevents the $\mathrm{K}^{+}$ions from exiting the cell, causing membrane depolarization, which also leads to opening of the voltage-dependent $\mathrm{Ca}^{2+}$ channels on the membrane, allowing for the entrance of $\mathrm{Ca}^{2+}$ into the cell, increasing its cytosol concentration, and finally inducing granule exocytosis. Sulfonylureas bind to the SUR1 component of the KATP channel (see text for further details). GLUT: glucose transporter; SU: sulfonylureas; SUR1: sulfonylurea receptor subunits; ATP: adenosine triphosphate. Source: author's elaboration.

The fact that KATP channels explain glucose's metabolic and electrophysiological effects also allowed us to identify that these channels are the cellular target of sulfonylureas (SUs). The ability of these drugs to induce the closure of KATP channels explains their usefulness and efficacy in the oral management of individuals with T2DM. The $\beta$-cell KATP channel is a heterotetramer that is made up of four $\mathrm{K}^{+}$channel subunits (Kir6.2) and four SU receptor subunits (SUR1) (Fig. 2) [20, 21].

After eating a meal, there is a rapid and large release of insulin from the $\beta$ cells (known as the first phase of insulin secretion). In this phase, the peripheral uptake of other nutrients is promoted (in addition to the suppression of hepatic gluconeogenesis). Finally, the possibility of significant increases in postprandial blood glucose levels is decreased [22].

Meanwhile, the second phase of insulin secretion (after eating a meal) is established more slowly and continuously and is sustained until the blood glucose level returns to normal (unlike the first phase, wherein insulin secretion occurs quickly and in the short term). Additionally, the second phase has the characteristic of being independent of the extracellular glucose level (Fig. 3) [23].

Paradoxically, a significant number of individuals with prediabetes (impaired fasting glucose, impaired glucose tolerance, or both) may be hyperinsulinemic. However, insulin secretion has been shown to decrease significantly before the diagnosis of diabetes is established. In fact, a PG value $\geq 198$ $\mathrm{mg} / \mathrm{dL}$ (after an oral glucose tolerance test) indicates that the insulin secretory capacity is reduced in relation to insulin resistance and hyperglycemia concomitant. Such "insulinopenia" is one of the defining characteristics of the onset of T2DM $[23,24]$. 


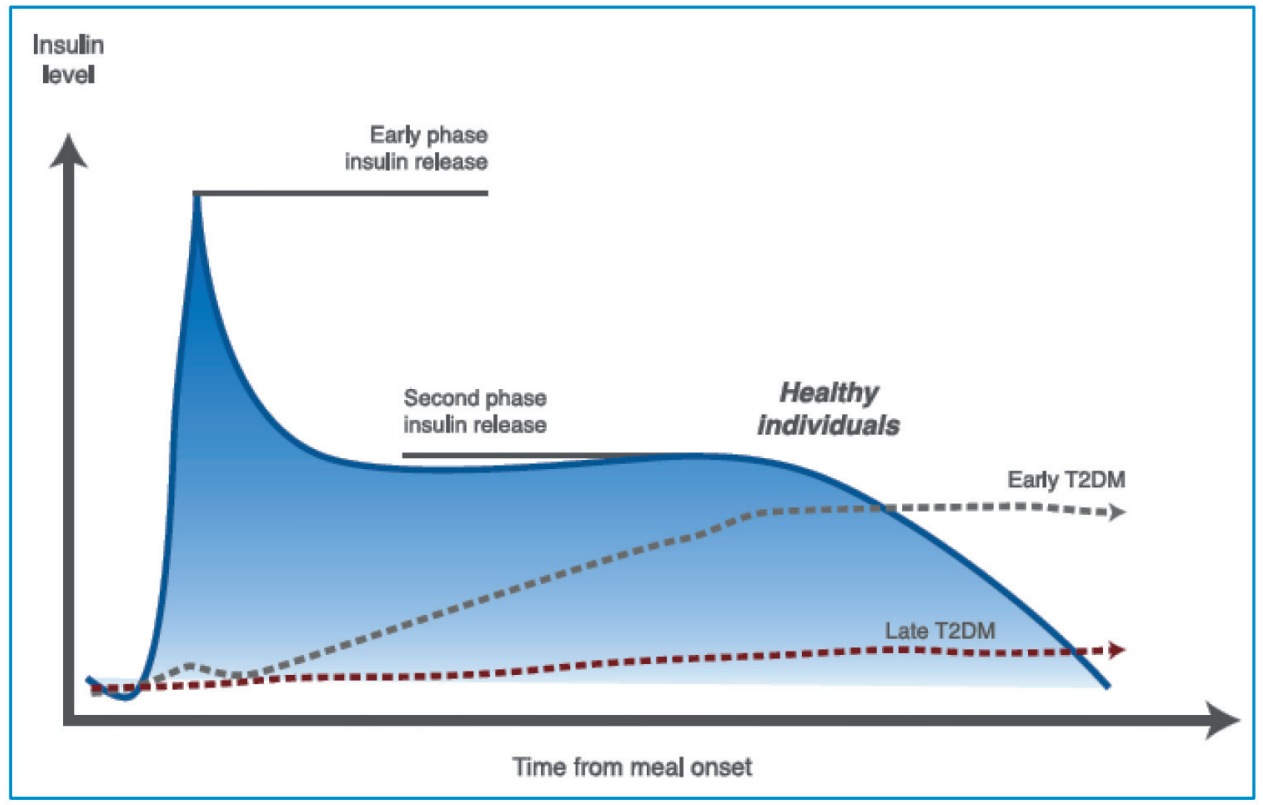

Figure 3. Insulin secretion phases in healthy and T2DM individuals. In early phase insulin release the $\beta$ cells produce insulin in response to rising glucose levels. Proinsulin (the precursor molecule) is cleaved into C-peptide and insulin. The "early phase insulin release" occurs within 2 min of glucose arriving in the blood stream and continues for about $10-15$ min. This phase prevents post-prandial hyperglycemia. A second phase of insulin release continues until blood glucose levels return to normal (see text for further details). T2DM: type 2 diabetes mellitus. Source: author's elaboration.

\section{Why, When, and How to Initiate?}

\section{Why initiate}

The development of injectable insulin therapies for T2DM presents unique challenges not evident in other classes of antidiabetic therapies. Insulin is the only antidiabetic therapy available for which there is no maximal dose for efficacy. However, achieving the therapeutic goals is countered by the risk and the fear of hypoglycemia, and both serve as barriers to tight glycemic control with the most effective antidiabetic agent available. This risk, alongside weight gain and the subcutaneous route of administration, often leads to insulin being relegated to a last-option therapy [25].

\section{When to initiate}

In the clinical setting, it is sometimes difficult to define the right moment when BIs management should be considered in individuals with T2DM (who do not achieve metabolic control); different international organizations make different recommendations in this regard (Table 1) [26-28]. Likewise, it is clear that the higher the $\mathrm{A} 1 \mathrm{c}$, the stronger the requirement for BIs management. Hence, it has been shown that when the A1c is $<7.5 \%$, the primary determinant of this value is postprandial glycemia, and when the A1c is $>8.5 \%$, the primary determinant is fasting glucose levels (Fig. 4) [29]. This concept is the foundation to considering the use of $\mathrm{BI}$ in patients with very high A1c levels. Therefore, the higher the A1c, the stronger the indication for BI use since its use is intended to reduce hepatic glucose production (the primary source of increased fasting blood sugar) and limit nocturnal and interprandial hyperglycemia $[29,30]$.

This "balance" between fasting plasma glucose (FPG), postprandial glycemia (PPG), and A1c level is essential when considering the use or the requirement for $\mathrm{BI}$ and the use of drugs with a postprandial effect (GLP-1RA).

\section{How to initiate}

There are several ways to calculate the starting dose of the BIs. One such method can be dividing the average value of the PG by 18; another way is dividing an individual's body weight by 10 . However, in RCTs, it is usually started with a dose of $0.1-0.2 \mathrm{U} / \mathrm{kg} /$ day (or with a dose of $10 \mathrm{U} /$ day). Regardless of the initial insulinization strategy, what is truly important is to guarantee an adequate and permanent titration (Table 2) [3032].

Moreover, there has always been a debate around establishing a limit or "ceiling" of the BI dose. It has been said that when a patient has reached the "ceiling" dose for BI of 0.5 $\mathrm{U} / \mathrm{kg} /$ day and has not been able to reach the target metabolic control, insisting on increasing the BI dose increases the risk of hypoglycemia, with a significant body weight increase (and little impact on A1c) [31, 32].

Therefore, in the case of a patient who titrated the BI dose up to $0.5 \mathrm{U} / \mathrm{kg} /$ day, failing to accomplish the pre-established goals, the recommendation is to intensify treatment either with a basal-plus or basal-bolus regimen or with premixed insulins 
Table 1. Recommendations for Considering the Initiation of BI Therapy in T2DM

Overall recommendations [26-28]

Deterioration of insulin secretion or phenotypical characteristics associated with early insulin requirement (LADA) or autoantibodies positive against any pancreatic islet component

Symptomatic hyperglycemia (weight loss, polyuria, polydipsia, polyphagia, tendency to ketosis)

Inability to increase $\mathrm{C}$-peptide following glucagon stimulation

Inability to maintain acceptable glucose levels despite diet, exercise and maximum doses of $\geq 2$ OADs, one of which must be an insulin secretion enhancer

Concomitant conditions or diseases (pancreatitis, pancreatic cancer, pancreatectomy, liver cirrhosis, chronic steroid therapy, anti-retroviral therapy, inter alia)

Patient preferences

Recommendations according to different international organizations

AACE, 2019 [27]

Individuals receiving dual or triple therapy and $\mathrm{A} 1 \mathrm{c} \geq 7.5 \%$, or patients with $\mathrm{A} 1 \mathrm{c}>9.0 \%$ with associated symptoms

ADA, 2022 [26]

Individuals with evidence of weight loss, or in the presence of hyperglycemic symptoms, or when the Alc is $>10 \%$, or when glycemia is $\geq 300 \mathrm{mg} / \mathrm{dL}$

Diabetes Canada, 2018 [28]

Insulin may be used at any time in people not achieving glycemic targets while on noninsulin antihyperglycemic medication(s)

AACE: American Association of Clinical Endocrinologists and American College of Endocrinology; ADA: American Diabetes Association; BI: basal insulin; C-peptide: connecting peptide; LADA: latent autoimmune diabetes in adults; OADs: oral antihyperglycemic agents; T2DM: type 2 diabetes mellitus.

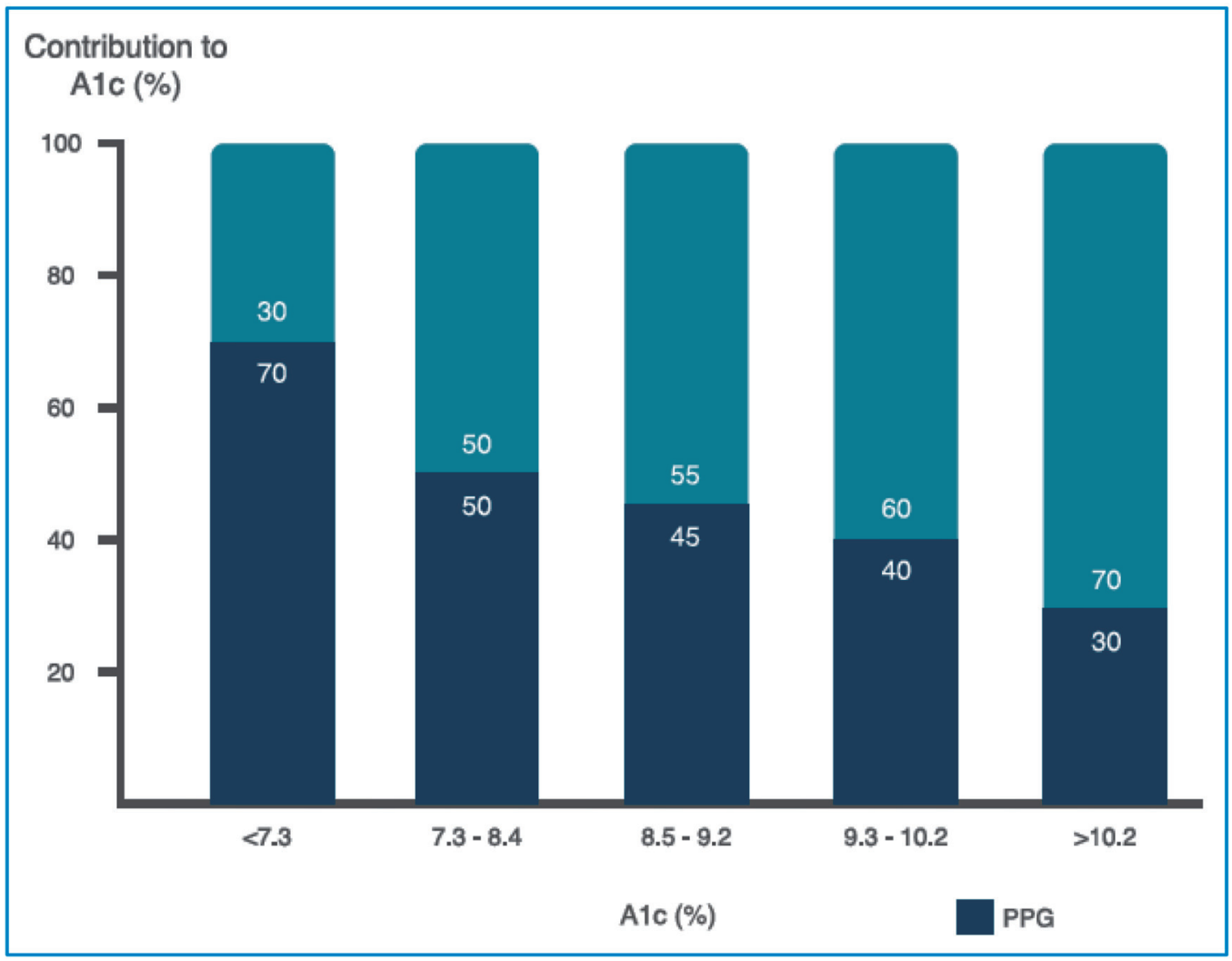

Figure 4. Relative contribution of FPG and PPG across a broad range of A1c levels (see text for further details). FPG: fasting plasma glucosa, PPG: postprandial plasma glucose. Source: adapted from Ref. [29]. 
Table 2. General Recommendations for Starting the BI Dose and for Adjusting When Switching From One Insulin to Another [30-32]

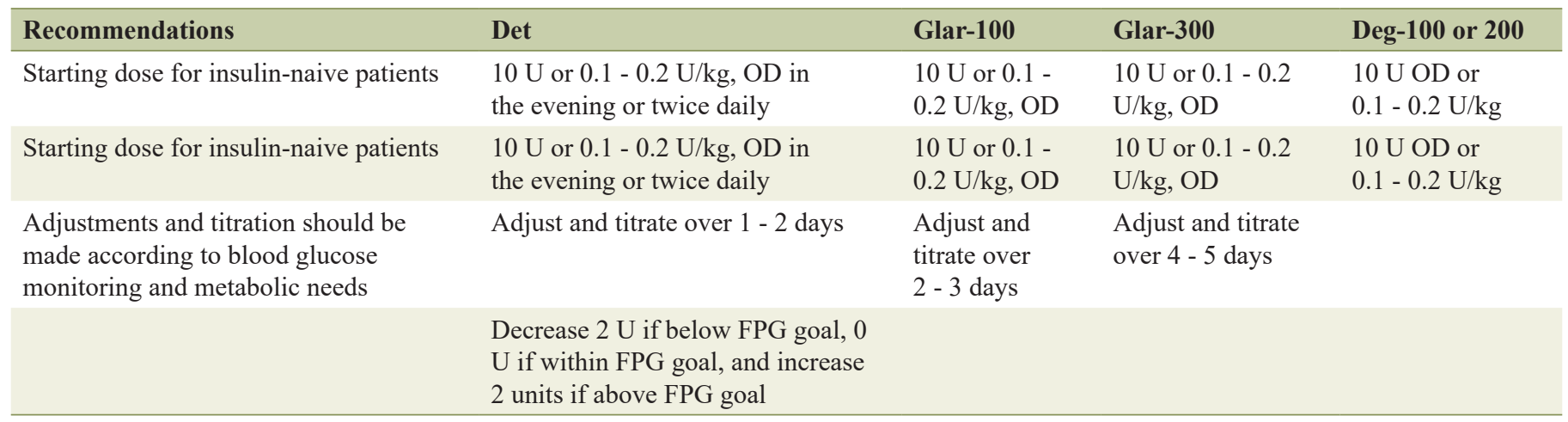

BI: basal insulin; Deg: degludec; Det: detemir; FPG: fasting plasma glucose; Glar: glargine; NPH: neutral protamine Hagedorn; OD: once daily; U: units.

or a regimen with $\mathrm{BI}+\mathrm{GLP}-1 \mathrm{RA}$ (though intensification is also possible with OADs; for example, inter alia, sodium glucose cotransporter-2 (SGLT2) inhibitors and dipeptidyl peptidase-4 (DPP-4) inhibitors) [26].

\section{Basic Concepts About Bls}

By definition, the duration of the effect over time of a BI should be prolonged, which is why, when classifying the different insulins with this characteristic, they are summarized as the following: neutral protamine Hagedorn (NPH), detemir (Det), and glargine-100 (Glar-100) and glargine-300 (Glar300), respectively, and degludec-100 (Deg-100) and degludec-200 (Deg-200), respectively. Among these, NPH insulin is considered an intermediate action BI (in relation to its effect in the time). The initial objective of BIs management is to normalize the FPG and, according to evolution and metabolic control, to focus later on PPG control $[33,34]$.

In clinical practice, a formula that evaluates the difference between PPG and FPG (divided by the value of FPG) may be useful. The result of this calculation ((PPG - FPG)/FPG) helps to establish whether the predominant origin of hyperglycemia in an individual is due to the PPG or the FPG. Thus, the higher the value (of this calculation), the greater the influence of the PPG; on the contrary, with a lower said result, it can be concluded that the resulting hyperglycemia is predominantly due to FPG. The importance of making this calculation is that, in the first case, the use of rapid-acting insulin analogs (lispro, aspart, or glulisine), regular insulin, or insulin premixes may be the first management option. In the second case, the main option would be the use of BIs. It may also be useful to evaluate the relationship between FPG and A1c since, with a result $\geq 1.3$, it would indicate that the main component of hyperglycemia is fasting glucose [35].

From the moment they are absorbed and reach the bloodstream, all BIs have the same mechanism of action on the tissues in which they act. The challenge in the generation of new BIs is to develop strategies that delay the absorption of the molecule, prolonging its half-life and causing a lower frequency of "peaks" and "valleys". For example, available BIs have a longer half-life thanks to a variety of mechanisms such as, inter alia, the addition of protamine or albumin and $\mathrm{pH}$ dependent precipitation, causing differences in their behavior once they are found in the subcutaneous tissue, which modifies its rate of absorption (thus called "insulin protraction") [36, 37].

\section{NPH}

NPH insulin was discovered in 1936. However, it was in 1946 that the first "isophane NPH" insulin became commercially available, combining insulin and protamine in stoichiometric amounts at a neutral $\mathrm{pH}$ (when it was shown that its effect by the subcutaneous route could be prolonged to the additional protamine). In this way, the insulin remained in "suspension" in the subcutaneous tissue, delaying the absorption time, thus prolonging its half-life [38].

The onset of action of NPH is approximately $2 \mathrm{~h}$, and its maximum effect and duration are $6-14$ and $10-16 \mathrm{~h}$, respectively. These characteristics have led to classifying NPH as an "intermediate" acting insulin. Therefore, if it is administered at bedtime, it can be considered a BI, while if it is administered in the morning, it can be considered an insulin basal/prandial. In general terms, the usual range of NPH doses is between 10 and $80 \mathrm{U}$, and it is considered that when it is used in low doses (i.e., $10 \mathrm{U} /$ day), it behaves with a lower rate of "peaks" and with a shorter half-life, while in high doses a higher rate of "peaks" with a longer half-life is observed $[39,40]$.

\section{Det}

Det insulin is a long-acting analog, which differs from human insulin in that an amino acid has been omitted at position B30 and a fatty acid chain (C14) has been added to amino acid B29. Additionally, and to adjust the $\mathrm{pH}$ (Det has a $\mathrm{pH}$ of 7.4), substances such as sodium hydroxide or hydrochloric acid can be added. When used in low doses, the half-life of Det is close to $6 \mathrm{~h}$, while in high doses, it can be as long as $24 \mathrm{~h}$. Det has a slower and longer absorption than NPH, its maximum serum 
Table 3. PK and PD Characteristics of BIs [34-37]

\begin{tabular}{llllll} 
Characteristic & NPH & Det & Glar-100 & Glar-300 & Deg-100 and Deg-200 \\
\hline Peak (h) & $4-8$ & $4-7$ (relatively flat) & No pronounced & Close to peakless (flat) & Close to peakless (flat) \\
Duration of action (h) & $10-16$ & $\leq 24$ & Up to 24 & $\geq 24$ to $\leq 36$ & $\leq 42$ \\
Half-life (h) & 4 & $5-7$ & $12-14$ & 23 & 25 \\
Dosing frequency & OD or TD & OD or TD & OD & OD & OD \\
Time to steady-state & Unknown & 1 to $<2$ days & $2-3$ days & $4-5$ days & $4-5$ days \\
\hline
\end{tabular}

BI: basal insulin; Deg: degludec; Det: detemir; Glar: glargine; NPH: neutral protamine Hagedorn; OD: once daily; PD: pharmacodynamic; PK: pharmacokinetic; TD: twice daily.

concentration $\left(\mathrm{C}_{\max }\right)$ is achieved $6-8 \mathrm{~h}$ after its application, and it has a bioavailability of close to $60 \%$. Its main binding protein (once it reaches the circulation) is albumin [40-43].

\section{Deg}

Deg insulin is a long-acting analog and differs from human insulin in that the amino acid threonine has been omitted at position B30 and a side chain with glutamic acid and a C16 fatty acid has been added. This insulin forms soluble and stable dihexamers when phenol and zinc are added. Therefore, when phenol is injected into the subcutaneous tissue, it diffuses, causing the creation of a more soluble deposit (in the form of multihexamers). For its part, zinc undergoes a slower diffusion, allowing its release to be more gradual, continuous, and prolonged from the application site. These characteristics allow its half-life to be greater than $24 \mathrm{~h}$, with a durability of around $40 \mathrm{~h}[44,45]$.

Deg reaches its steady state after administration for 3 4 days. In this state, Deg-100 and Deg-200 behave similarly (when supplied in the same dose in $\mathrm{U} / \mathrm{kg}$ ). Therefore, concentrating the molecule (Deg-200) has not been shown to affect the formation of multihexamers or their absorption from the subcutaneous tissue (when compared to Deg-100) [46, 47].

In general, the elimination $t_{1 / 2}$ is considered the time it takes for the amount of insulin in the blood to drop by half. Therefore, from the moment the maximum concentration of insulin in the circulation is reached, at least four half-lives of insulin elimination must elapse to achieve an almost complete elimination (which explains why it requires 4 - 5 half-lives to achieve its steady state). This concept is inherent to all BIs [48].

\section{Glar-100 and Glar-300}

Glar insulin is a long-acting analog in which two arginine molecules have been added to chain B (in the C-terminal region), and the amino acid arginine has been replaced by glycine in chain A (in position 21). These modifications cause a change in the isoelectric point of the $\mathrm{pH}$, from 5.4 to 6.7 , which causes the insulin to be less soluble in the subcutaneous tissue, thus producing microprecipitates. Additionally, zinc is added (so that it crystallizes in the subcutaneous tissue), and its absorption is further delayed [49].
The action of Glar begins 1 - $2 \mathrm{~h}$ after its application, maintaining a constant concentration profile in plasma (peakless), which is sustained for $20-24 \mathrm{~h}$. Two presentations are commercially available: Glar-100 (100 U/mL) and Glar-300 $(300 \mathrm{U} / \mathrm{mL})$. Glar is metabolized into two active metabolites: M1 and M2 (21A-Gly-insulin and 21A-Gly-des-30B-Thr-insulin, respectively) [50].

The main circulating metabolite of Glar-100 is M1, which increases according to the dose supplied. At the pharmacokinetic (PK) and pharmacodynamic (PD) levels, it has been found that the effects after the application of Glar-100 are mainly based on the metabolite M1. For its part, the M2 metabolite is not detectable in most individuals exposed to Glar100. However, when detected, its concentration is independent of the administered dose of insulin. With Glar-100, the steady state is reached 2 - 4 days after the first dose (once a day) [51, 52].

For its part, the Glar-300 is characterized by being more concentrated than the Glar-100, with a PK profile where its effect is more prolonged and "flat" (compared to Glar-100). This allows its steady state to be reached in over 5 days, with less "variability" among those who receive it $[52,53]$. The PK and PD characteristics of the BI are summarized in Table 3 [34-37].

\section{Efficacy and Safety of BI}

In general, the PK and PD characteristics of the long-acting BIs (Det, Glar-100, Glar-300, Deg-100, and Deg-200) allow the widely known pattern of insulin secretion (from $\beta$ cell) to be imitated. Clinically, it resulted in lower rates of hypoglycemia, with a similar efficacy (i.e., Det vs. NPH, and Glar-100 vs. NPH) (Fig. 5) [40, 43, 52, 54, 55]. Likewise, no RCTs have compared the efficacy of Deg-100, Deg-200, or Glar-300 with NPH. Whereas, head-to-head studies among long-acting BIs have found that Det and Glar-100 have similar efficacy and safety profiles (relative to the risk of hypoglycemia) (Table 4) $[40-43,56]$. Similarly, Deg-100 and Glar-100 denote similar efficacy, with a lower risk of hypoglycemia (nocturnal) with Deg-100 [57]. Additionally, the RCTs that have compared Glar-300 with Glar-100 also show that the efficacy is similar, but the risk of overall (anytime) and nocturnal hypoglycemia is lower with Glar-300 (Fig. 6) [57-59]. Moreover, the studies evaluating the efficacy and safety of the more recently approved long-acting BIs (Deg-100, Deg-200, and Glar-300) 

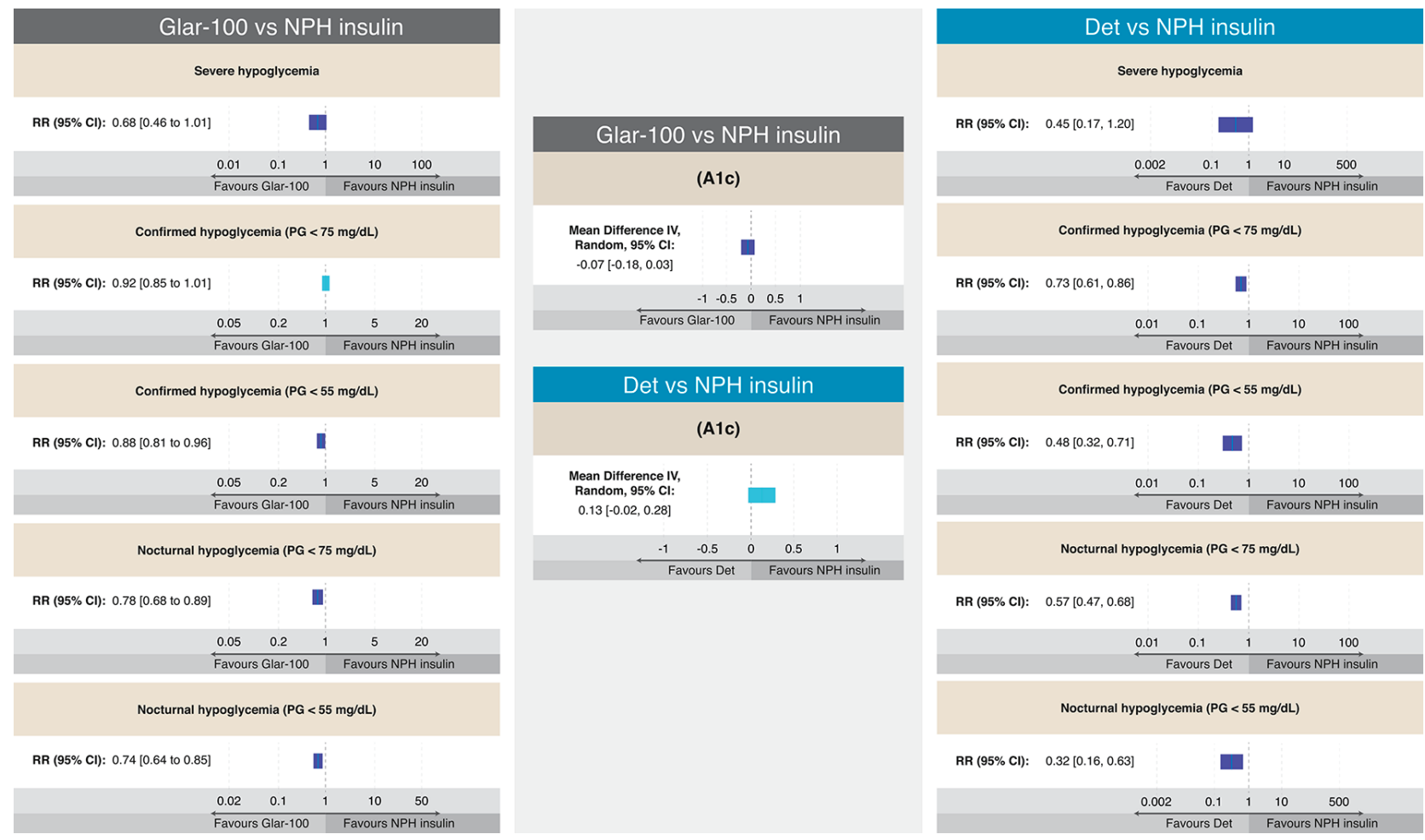

Figure 5. Efficacy and results on different definitions of hypoglycemia from RCTs comparing Glar-100 vs. NPH and Det vs. NPH in T2DM. The figure summarizes the different results of the RCTs that evaluated the safety and efficacy of Glar- $100 \mathrm{vs.} \mathrm{NPH}$ (data extracted and adapted from Refs. [54] and [55]) and Det vs. NPH (data extracted and adapted from Refs. [40], [43], and [55]). Studies comparing Glar-100 vs. NPH showed differences favoring Glar-100 in three aspects: confirmed hypoglycemia $(P G<55 \mathrm{mg} / \mathrm{dL})$, nocturnal hypoglycemia ( $P G<75 \mathrm{mg} / \mathrm{dL}$ ) and nocturnal hypoglycemia $(P G<55 \mathrm{mg} / \mathrm{dL})$. On the other hand, the studies that compared Det vs. NPH showed differences, favoring Det in four aspects: confirmed hypoglycemia (PG $<75$ $\mathrm{mg} / \mathrm{dL}$ and $<55 \mathrm{mg} / \mathrm{dL}$ ), nocturnal hypoglycemia ( $P G<75 \mathrm{mg} / \mathrm{dL}$ and $<55 \mathrm{mg} / \mathrm{dL}$ ). No differences were found in the $A 1 \mathrm{c}$ value between Glar-100 vs. NPH or between Det vs. NPH. Cl: confidence interval; Det: detemir; Glar: glargine; NPH: neutral protamine Hagedorn; PG: plasma glucosa; RCTs: randomized clinical trials; RR: risk ratio; T2DM: type 2 diabetes mellitus. Source: author's elaboration.

Table 4. Efficacy and Risk of Hypoglycemia From RCTs Comparing Det vs. Glar-100 in T2DM [40-43]

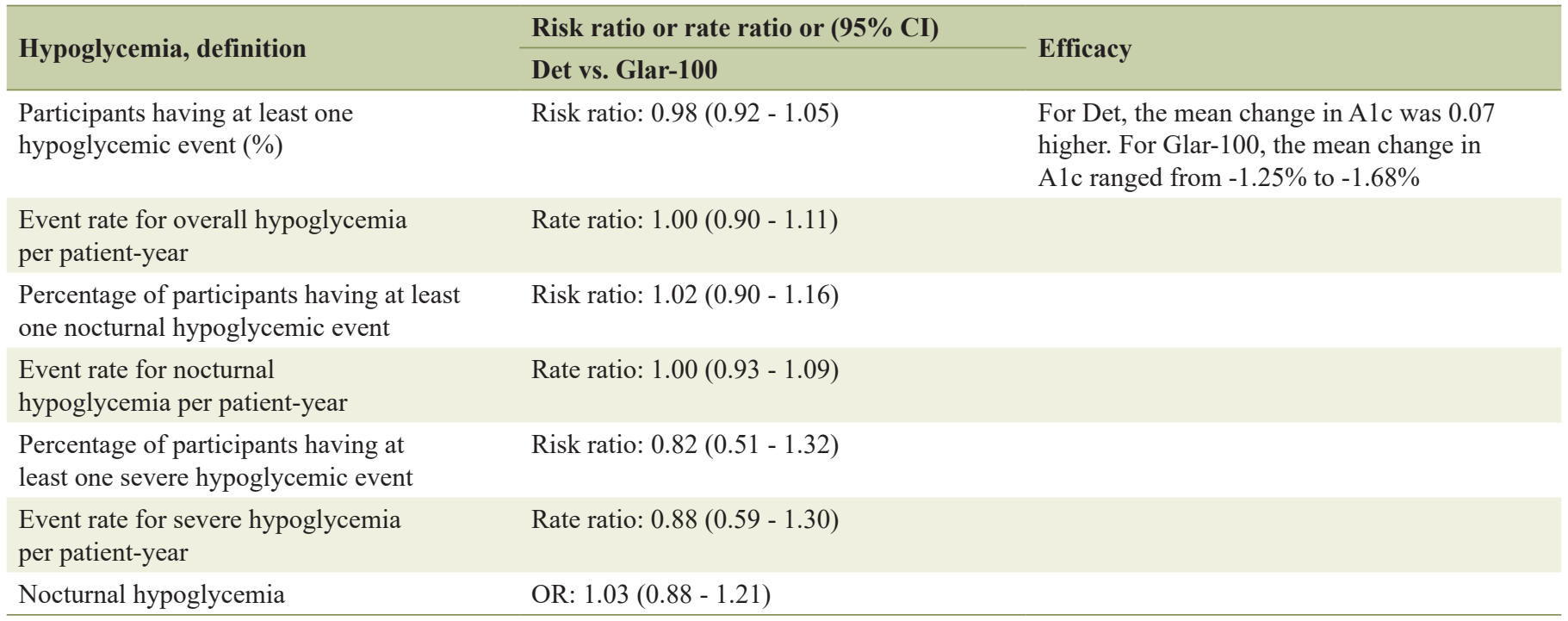

Cl: confidence interval; Det: detemir; Glar: glargine; NOP: number of participants; OR: odds ratio; RCTs: randomized clinical trials; T2DM: type 2 diabetes mellitus. 


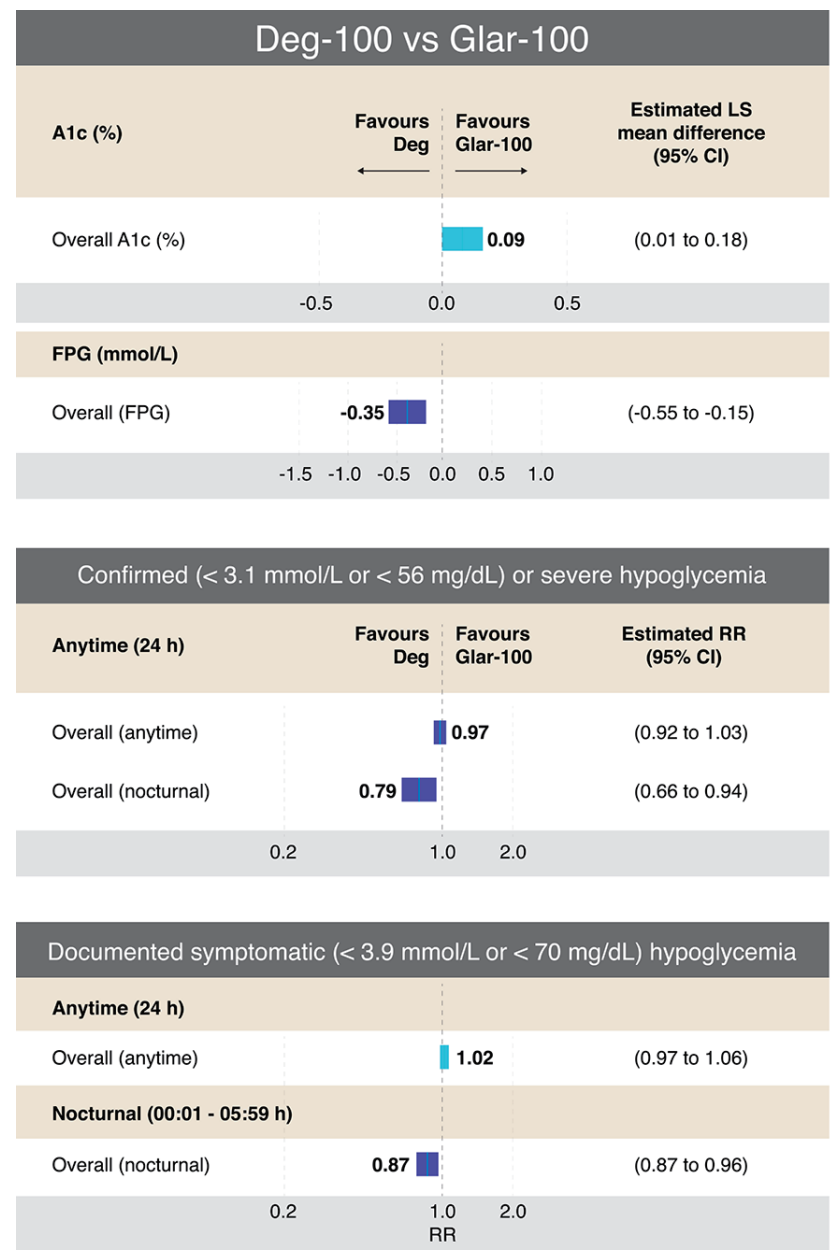

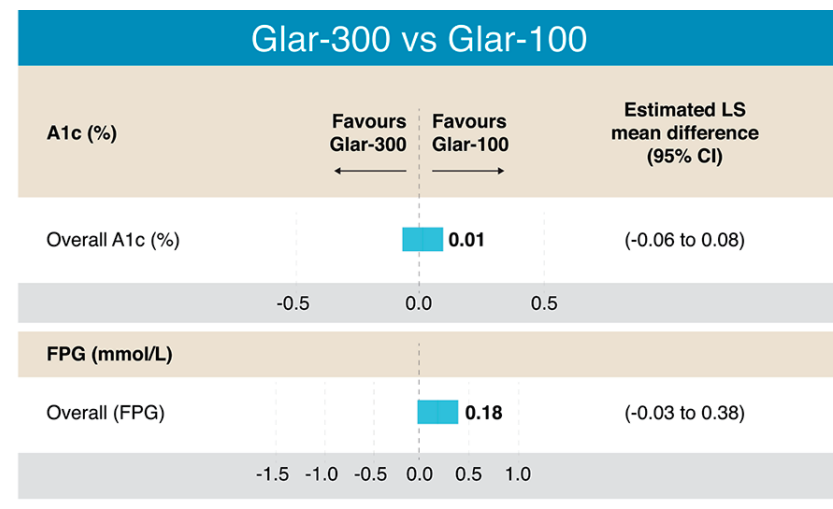

Confirmed $(<3.0 \mathrm{mmol} / \mathrm{L}$ or $<54 \mathrm{mg} / \mathrm{dL}$ ) or severe hypoglycemia

\begin{tabular}{|c|c|c|c|}
\hline Anytime (24 h) & $\begin{array}{l}\text { Favours } \\
\text { Glar-300 }\end{array}$ & $\begin{array}{l}\text { Favours } \\
\text { Glar-100 }\end{array}$ & $\begin{array}{l}\text { Estimated RR } \\
(95 \% \mathrm{Cl})\end{array}$ \\
\hline Overall (anytime) & 0.81 & & ( 0.69 to 0.94 ) \\
\hline Overall (nocturnal) & 0.75 & & (0.61 to 0.92$)$ \\
\hline & & 2.0 & \\
\hline
\end{tabular}

Documented symptomatic ( $<3.9 \mathrm{mmol} / \mathrm{L}$ or $<70 \mathrm{mg} / \mathrm{dL}$ ) hypoglycemia

Anytime (24 h)

\begin{tabular}{|c|c|c|c|}
\hline Overall (anytime) & 0.89 & & (0.83 to 0.95$)$ \\
\hline \multicolumn{4}{|c|}{ Nocturnal (00:00 - 05:59 h) } \\
\hline Overall (nocturnal) & 0.74 & & (0.65 to 0.83 ) \\
\hline & $\begin{array}{l}1.0 \\
\text { RR }\end{array}$ & 2.0 & \\
\hline
\end{tabular}

Figure 6. Efficacy and results on different definitions of hypoglycemia from RCTs comparing Deg-100 vs. Glar-100 and Glar-300 vs. Glar-100 in T2DM. The figure summarizes the different results of the RCTs that evaluated the safety and efficacy of Deg-100 vs. Glar-100 (data extracted and adapted from Refs. [57] and [58]) and Glar-300 vs. Glar-100 (data extracted and adapted from Refs. [58] and [59]). The studies that compared Deg-100 vs. Glar-100, showed differences in favor of Glar- 100 on the A1c value, while the FPG value was significantly reduced with Deg-100. Differences in favor of Deg-100 were also found in two aspects: confirmed or severe hypoglycemia and documented symptomatic (overall and nocturnal ( $\mathrm{PG}<56 \mathrm{mg} / \mathrm{dL}$ and $<70 \mathrm{mg} / \mathrm{dL}$, respectively). On the other hand, the studies that compared Glar-300 vs. Glar-100 found no differences in the A1c value; however, differences were found in favor of Glar-300 in four aspects: confirmed severe hypoglycemia (<54 mg/dL, overall (anytime) and overall (nocturnal)), and in documented symptomatic hypoglycemia (<70 mg/dL, overall (anytime) and overall (nocturnal)). Cl: confidence interval; Deg: degludec; FPG: fasting plasma glucosa; Glar: glargine; PG: plasma glucosa; RCTs: randomized clinical trials; RR: risk ratio; T2DM: type 2 diabetes mellitus. Source: author's elaboration.

found that the efficacy of Glar-300 vs. Deg-100 is similar, with a profile safety in favor of Glar-300 on the risk of hypoglycemia (demonstrated only in the insulin titration period, defined between week 0 and 12). Finally, no differences were found in the efficacy or the risk of hypoglycemia when comparing Glar300 and Deg-200 (Fig. 7) [58, 60-62].

On the other hand, studies have shown that, in relation to weight, Det showed less weight gain than NPH and Glar-100. Likewise, a lower weight gain was documented with Glar300 than Glar-100 (Table 5) [38-40, 56-63]. Moreover, when evaluating the average doses of BI, it was found that with the use of Deg-100, a lower dose was required (compared to Glar100), while with Glar-300, a higher average dose was required (compared to Glar-100) [58,59].

\section{Discussion}

Historically, insulin treatment has been considered a third or fourth management option in individuals with T2DM by a significant number of clinicians (and most patients). The concept is that the use of insulin should only be considered when all other nonparenteral options have been exhausted, despite the different recommendations of numerous international organizations, management guides, and expert committees [62].

However, it must be taken into account that many patients with T2DM can be managed with OADs together with BIs (basal-supported oral therapy (BOT)); the availability of drugs with different mechanisms of action (DPP-4 inhibitors, 


\section{Glar-300 vs Deg-100 [Anytime (24-h) hypoglycemia]}

\begin{tabular}{|c|c|c|c|c|c|c|c|}
\hline \multicolumn{8}{|c|}{ Incidence \% } \\
\hline $0-12$ weeks & Glar-300 & Deg-100 & OR $(95 \% \mathrm{Cl})$ & $P$ value & & & \\
\hline Confirmed $(\leq 70 \mathrm{mg} / \mathrm{dL}[\leq 3.9 \mathrm{mmol} / \mathrm{L}])$ & 47.4 & 54.3 & 0.74 (0.57 to 0.97$)$ & 0.030 & & & \\
\hline Confirmed $(\leq 54 \mathrm{mg} / \mathrm{dL}[\leq 3.0 \mathrm{mmol} / \mathrm{L}])$ & 7.8 & 11.7 & 0.63 (0.40 to 0.99$)$ & 0.040 & & 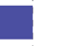 & \\
\hline \multicolumn{5}{|c|}{ OR (95\% Cl) } & 0.3 & 1.0 & 3.0 \\
\hline & & & & & Favours & & Favours Deg-100 \\
\hline
\end{tabular}

Event rate (events per patient-year)

0-12 weeks

Confirmed ( $\leq 70 \mathrm{mg} / \mathrm{dL}[\leq 3.9 \mathrm{mmol} / \mathrm{L}]$ )

Confirmed ( $\leq 54 \mathrm{mg} / \mathrm{dL}[\leq 3.0 \mathrm{mmol} / \mathrm{L}]$ )

$\begin{array}{cc}\text { Glar-300 } & \text { Deg-100 } \\ 8.08 & 10.47 \\ 0.49 & 0.86\end{array}$

\section{OR $(95 \% \mathrm{Cl})$}

0.77 (0.62 to 0.96$)$

0.57 (0.34 to 0.97$)$
$\boldsymbol{P}$ value

0.023

0.038

$\mathbf{R R}(95 \% \mathrm{CI})$

0.3

Favours Glar-300
$1.0 \quad 3.0$

Favours Deg-100

Deg-200 vs Glar-300, RR (95\% Cl)

Rate of hypoglycemia

Overall symptomatic

$0.88(0.73,1.06)$

$0.0625 \quad 0.125$

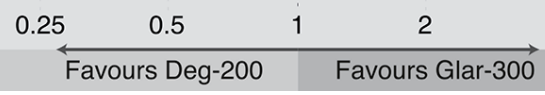

Figure 7. Outcomes on different definitions of hypoglycemia from RCTs comparing Glar-300 to Deg-100 and Deg-200 to Glar300 in T2DM. The only head-to-head study that has compared Glar-300 vs. Deg-100, showed differences favoring Glar-300 on the risk of confirmed hypoglycemia ( $\leq 70 \mathrm{mg} / \mathrm{dL}$ and $\leq 54 \mathrm{mg} / \mathrm{dL}$ ) only in the insulin titration period ( 0 - 12 weeks); data extracted and adapted from Refs. [58] and [60]. On the other hand, the only head-to-head study that compared Deg-200 vs. Glar-300 found no difference in the risk of overall hypoglycemia (data extracted and modified from Refs. [61] and [62]). In both studies no differences were found on the A1c value. Cl: confidence interval; Deg: degludec; Glar: glargine; OR: odds ratio; RR: risk ratio; T2DM: type 2 diabetes mellitus. Source: author's elaboration.

Table 5. Effects on Body Weight and Differences in the Average Dose of the Different Bls in T2DM

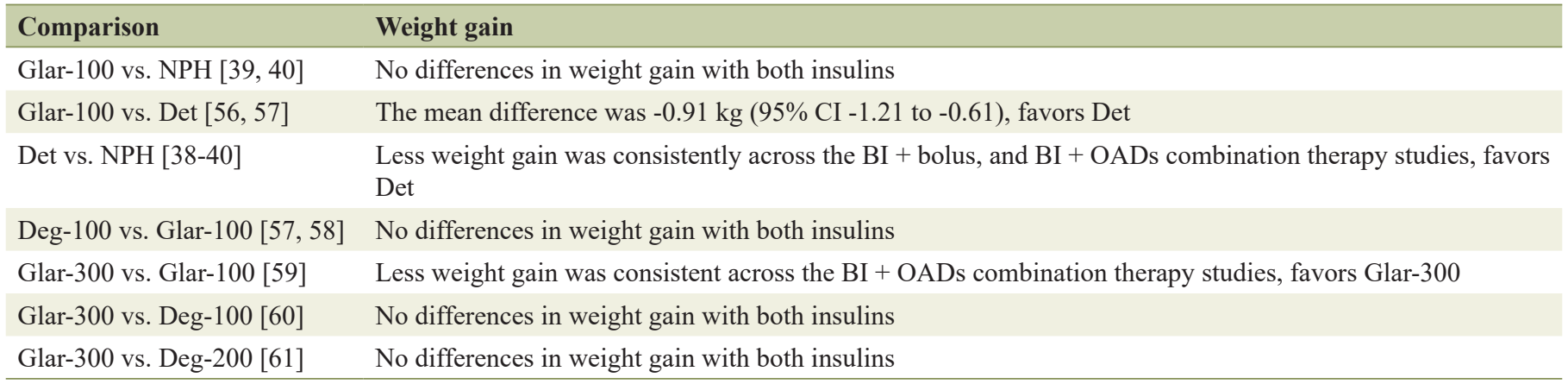

BI: basal insulin; Deg: degludec; Det: detemir; Glar: glargine; NPH: neutral protamine Hagedorn; OAD: oral antihyperglycemic drug; T2DM: type 2 diabetes mellitus. 
metformin, SGLT2 inhibitors, SU, thiazolidinediones (TZDs), inter alia) does not contraindicate the use of BOTs; however, it must be taken into account that the combination of SU with BIs increases the risk of weight gain and hypoglycemia; moreover, the use of TZDs with BIs can also induce significant weight gain. Therefore, any BOT scheme must be individualized, always establishing the risks (weight gain and a higher rate of hypoglycemia) and the potential benefits, since management with BIs could help to suspend OADs in compromised individuals of renal and/or hepatic function, or in those receiving multiple OADs or in situations where these drugs are considered to have progressively lost their efficacy (such as SUs) or where it is considered that there is a risk of other outcomes, for example, heart failure (for TZDs) [26-28].

On the other hand, the use of BIs with GLP-1RAs is a useful and effective management strategy. Potentially, all GLP-1RAs can be combined with BIs, this combination has shown greater efficacy in the control of A1c, FPG and PPG (in relation to the exclusive use with BI or with GLP-1RAs, in individuals with T2DM receiving management with OADs); it is currently considered that any individual with T2DM in treatment with OADs with A1c levels $>10.0 \%$ (or with levels that exceed the value of the Alc two percentage points above the "individual" goal) can benefit from the combined treatment BIs + GLP-1RA [26, 64].

Two titratable, fixed-ratio combination (FRC) therapies are currently available, Glar-100/lixisenatide (GlarLixi) and Deg-100/liraglutide (DegLira); both combinations have shown greater efficacy in metabolic control (A1c, FPG, and GPP) with a lower risk of hypoglycemia, less weight gain, and a lower dose of insulin (when compared to either of the two BIs in monotherapy). A lower risk of gastrointestinal adverse events (when compared to either of the two GLP-1RAs) has also been documented. It should be taken into account that, when an individual has the indication for the combination BI + GLP-1RAs, if one of the objectives of management is to reduce the risk of cardiovascular events, then it is recommended to use each one of the components separately, since for the available presentation (DegLira) the only way for the patient to receive the dose of Lira that has been shown to reduce the risk of cardiovascular outcomes $(1.8 \mathrm{mg})$, is supplying at the same time a dose of Deg of $50 \mathrm{U}[64,65]$.

Despite the benefits of early initiation of insulin on metabolic control, the preservation of $\beta$ cells and the potential benefit of reducing vascular complications are clear. There are still doubts and misconceptions surrounding the initiation and intensification of insulin management, and among these are the patient's fear of using needles, the time required for the application of insulin, social stigmatization, risk of hypoglycemia, impact on weight gain, and cost of modern insulins [66].

Although each of these conditions could eventually be understood and justified from the perception of the patient, the treating physician may not believe that to be the case. Ultimately, all of these factors translate into therapeutic inertia, poor metabolic control, and an unacceptably high risk of microvascular, macrovascular, and mortality outcomes $[67,68]$.

In this review, it has been described that the efficacy of all of the insulins available and considered as BI have a similar efficacy. The differences found between long-acting analog insulins and NPH insulin are based on the former showing a profile of improved safety compared to NPH. With a lower risk of hypoglycemia (as well as the advantage of being able to be applied once a day), these aspects clearly explain why long-acting BIs are preferred in the clinical setting. However, in places where the cost and access to long-acting analog insulins make their use difficult, NPH continues to be valid and useful [69]. In these cases, the benefit outweighs the potential risk of hypoglycemia from NPH.

In those clinical scenarios where access to all BIs is not an inconvenience (as is the cost), the decision to choose one or the other insulin should be based on aspects such as the lower risk of hypoglycemia, lower increase in weight, and lower frequency of applications throughout the day. In accordance with the above, BIs such as Glar-100, Glar-300, Deg-100, and Deg200 should be preferred in relation to Det.

Likewise, the lower risk of hypoglycemia found with insulins such as Deg-100 and Glar-300 makes their use more likely to be preferred (in relation to Glar-100). Moreover, the lower increase in weight documented with Glar-300 is an additional benefit. In this sense, it can be argued that in cases where an individual under treatment with Glar-100 has an unacceptably high frequency of hypoglycemia or where a therapeutic objective is weight reduction (or at least no weight gain), it is reasonable to consider a switch to insulins such as Deg-100 or Glar-300 (with greater evidence of benefit for body weight than Glar-100) [70, 71].

On the other hand, in insulin-naive individuals, who require the initiation of BIs, the use of Glar-300, Deg-100, and Deg-200 is perfectly valid. However, when there is a scenario in which the patient has a higher risk of hypoglycemia a priori (mainly in the insulin titration period), the use of Glar-300 could be preferred over Deg-100. However, this has not been shown to result in higher adherence, lower risk of hypoglycemia, or better long-term metabolic control.

Finally, the improvement and advances in the development and generation of long-acting BIs should provide greater peace of mind and safety for both the treating physician and the patient, and this should be reflected (at least a priori) in less therapeutic inertia, in fewer doubts and fears in insulin management in individuals with T2DM.

\section{Conclusion}

In the clinic, it is not always easy to decide the ideal moment to start BIs management in individuals with T2DM. However, when making this decision, some key aspects must always be considered, such as, inter alia, metabolic control (FPG, PPG, and A1c), risk of hypoglycemia, effect on body weight, and frequency of application. In this sense, long-acting BIs have some advantages over NPH and Det insulin. Likewise, along with inducing a lower risk of hypoglycemia and less weight gain than Glar-100, Glar-300 also has an advantage over Deg100 in that it produces lower risk of hypoglycemia (specifically in the insulin titration period). Finally, between Glar-300 and Deg-200, there are more similarities in efficacy and safety than differences between both. 


\section{Acknowledgments}

None to declare.

\section{Financial Disclosure}

The author declares that he has not received any economic or financial incentive when making this manuscript.

\section{Conflict of Interest}

Hernando Vargas-Uricoechea has received honoraria from Sanofi and Novo Nordisk as speaker and on advisory boards.

\section{Author Contributions}

The author carried out the literature search, the design of the tables and figures and wrote the final manuscript.

\section{Data Availability}

The author declares that data supporting the findings of this study are available within the article. However, any required additional information can be provided by the corresponding author.

\section{References}

1. Petersmann A, Muller-Wieland D, Muller UA, Landgraf R, Nauck M, Freckmann G, Heinemann L, et al. Definition, classification and diagnosis of diabetes mellitus. Exp Clin Endocrinol Diabetes. 2019;127(S 01):S1-S7.

2. Reed J, Bain S, Kanamarlapudi V. A review of current trends with type 2 diabetes epidemiology, aetiology, pathogenesis, treatments and future perspectives. Diabetes Metab Syndr Obes. 2021;14:3567-3602.

3. Galicia-Garcia U, Benito-Vicente A, Jebari S, LarreaSebal A, Siddiqi H, Uribe KB, Ostolaza H, et al. Pathophysiology of Type 2 Diabetes Mellitus. Int J Mol Sci. 2020;21(17):6275.

4. Dhawan S, Natarajan R. Epigenetics and type 2 diabetes risk. Curr Diab Rep. 2019;19(8):47.

5. Weir GC, Gaglia J, Bonner-Weir S. Inadequate beta-cell mass is essential for the pathogenesis of type 2 diabetes. Lancet Diabetes Endocrinol. 2020;8(3):249-256.

6. Priya G, Kalra S, Bahendeka S, Jawad F, Aye TT, Shahjada S, Sehgal A, et al. Initiation of basal bolus insulin therapy. J Pak Med Assoc. 2020;70(8):1462-1467.

7. Dimitriadis GD, Maratou E, Kountouri A, Board M, Lambadiari V. Regulation of postabsorptive and postprandial glucose metabolism by insulin-dependent and insulinindependent mechanisms: an integrative approach. Nutrients. 2021;13(1):159.
8. Kruger DF, Martin CL, Sadler CE. New insights into glucose regulation. Diabetes Educ. 2006;32(2):221-228.

9. Lefebvre PJ, Scheen AJ. Glucose metabolism and the postprandial state. Eur J Clin Invest. 1999;29(Suppl 2):16.

10. Hatting M, Tavares CDJ, Sharabi K, Rines AK, Puigserver P. Insulin regulation of gluconeogenesis. Ann N Y Acad Sci. 2018;1411(1):21-35.

11. Ostergaard M, Mishra NK, Jensen KJ. The ABC of insulin: the organic chemistry of a small protein. Chemistry. 2020;26(38):8341-8357.

12. Liu M, Weiss MA, Arunagiri A, Yong J, Rege N, Sun J, Haataja L, et al. Biosynthesis, structure, and folding of the insulin precursor protein. Diabetes Obes Metab. 2018;20(Suppl 2):28-50.

13. Marques RG, Fontaine MJ, Rogers J. C-peptide: much more than a byproduct of insulin biosynthesis. Pancreas. 2004;29(3):231-238.

14. Fu Z, Gilbert ER, Liu D. Regulation of insulin synthesis and secretion and pancreatic Beta-cell dysfunction in diabetes. Curr Diabetes Rev. 2013;9(1):25-53.

15. Antoszewski A, Feng CJ, Vani BP, Thiede EH, Hong L, Weare J, Tokmakoff A, et al. Insulin dissociates by diverse mechanisms of coupled unfolding and unbinding. J Phys Chem B. 2020;124(27):5571-5587.

16. Rorsman P, Braun M. Regulation of insulin secretion in human pancreatic islets. Annu Rev Physiol. 2013;75:155179.

17. Olson AL, Humphries K. Recent advances in understanding glucose transport and glucose disposal. F1000Res. 2020;9(F1000 Faculty Rev):639.

18. Thorens B. GLUT2, glucose sensing: and glucose homeostasis. Diabetologia. 2015;58(2):221-232.

19. Jacobson DA, Shyng SL. Ion channels of the islets in type 2 diabetes. J Mol Biol. 2020;432(5):1326-1346.

20. Bonfanti DH, Alcazar LP, Arakaki PA, Martins LT, Agustini BC, de Moraes Rego FG, Frigeri HR. ATP-dependent potassium channels and type 2 diabetes mellitus. Clin Biochem. 2015;48(7-8):476-482.

21. Tinker A, Aziz Q, Li Y, Specterman M. ATP-sensitive potassium channels and their physiological and pathophysiological roles. Compr Physiol. 2018;8(4):1463-1511.

22. Caumo A, Luzi L. First-phase insulin secretion: does it exist in real life? Considerations on shape and function. Am J Physiol Endocrinol Metab. 2004;287(3):E371-385.

23. Campbell JE, Newgard CB. Mechanisms controlling pancreatic islet cell function in insulin secretion. Nat Rev Mol Cell Biol. 2021;22(2):142-158.

24. Wysham C, Shubrook J. Beta-cell failure in type 2 diabetes: mechanisms, markers, and clinical implications. Postgrad Med. 2020;132(8):676-686.

25. Russell-Jones D, Pouwer F, Khunti K. Identification of barriers to insulin therapy and approaches to overcoming them. Diabetes Obes Metab. 2018;20(3):488-496.

26. American Diabetes Association Professional Practice Committee; American Diabetes Association Professional Practice Committee, Draznin B, Aroda VR, Bakris G, Benson G, Brown FM, et al. Summary of revisions: standards of medical care in diabetes-2022. Diabetes 
Care. 2022;45(Supplement 1):S4-S7.

27. Garber AJ, Handelsman Y, Grunberger G, Einhorn D, Abrahamson MJ, Barzilay JI, Blonde L, et al. Consensus statement by the American Association of Clinical Endocrinologists and American College of Endocrinology on the comprehensive type 2 diabetes management algorithm - 2020 executive summary. Endocr Pract. 2020;26(1):107-139.

28. Diabetes Canada Clinical Practice Guidelines Expert Committee. Diabetes Canada 2018 clinical practice guidelines for the prevention and management of diabetes in Canada. Can J Diabetes. 2018;42(Suppl 1):S1-S325.

29. Monnier L, Lapinski H, Colette C. Contributions of fasting and postprandial plasma glucose increments to the overall diurnal hyperglycemia of type 2 diabetic patients: variations with increasing levels of $\mathrm{HbA}(1 \mathrm{c})$. Diabetes Care. 2003;26(3):881-885.

30. Schernthaner G, Guerci B, Gallwitz B, Rose L, Nicolay C, Kraus P, Kazda C. Impact of postprandial and fasting glucose concentrations on $\mathrm{HbAlc}$ in patients with type 2 diabetes. Diabetes Metab. 2010;36(5):389-394.

31. Khunti K, Giorgino F, Berard L, Mauricio D, Harris SB. The importance of the initial period of basal insulin titration in people with diabetes. Diabetes Obes Metab. 2020;22(5):722-733.

32. Perreault L, Vincent L, Neumiller JJ, Santos-Cavaiola T. Initiation and titration of basal insulin in primary care: barriers and practical solutions. J Am Board Fam Med. 2019;32(3):431-447.

33. Gonzalvo JD. Introduction to basal insulin therapy: clinical management of diabetes. Am J Manag Care. 2018;24(6 Suppl):S87-S92.

34. Smyth T. Understanding the principles of insulin use in type 1 and type 2 diabetes management. Nurs Stand. 2021;36(1):61-66.

35. Silver B, Ramaiya K, Andrew SB, Fredrick O, Bajaj S, Kalra S, Charlotte BM, et al. EADSG guidelines: insulin therapy in diabetes. Diabetes Ther. 2018;9(2):449-492.

36. Pettus J, Santos Cavaiola T, Tamborlane WV, Edelman S. The past, present, and future of basal insulins. Diabetes Metab Res Rev. 2016;32(6):478-496.

37. Cheng AYY, Patel DK, Reid TS, Wyne K. Differentiating basal insulin preparations: understanding how they work explains why they are different. Adv Ther. 2019;36(5):1018-1030.

38. Saleem F, Sharma A. NPH Insulin. [Updated Jun 25, 2021]. In: StatPearls [Internet]. Treasure Island (FL): StatPearls Publishing; 2021. Available from: https:// www.ncbi.nlm.nih.gov/books/NBK549860/.

39. Brunner GA, Sendhofer G, Wutte A, Ellmerer M, Sogaard B, Siebenhofer A, Hirschberger S, et al. Pharmacokinetic and pharmacodynamic properties of long-acting insulin analogue NN304 in comparison to NPH insulin in humans. Exp Clin Endocrinol Diabetes. 2000;108(2):100105.

40. Peterson GE. Intermediate and long-acting insulins: a review of NPH insulin, insulin glargine and insulin detemir. Curr Med Res Opin. 2006;22(12):2613-2619.

41. Philips JC, Scheen A. Insulin detemir in the treatment of type 1 and type 2 diabetes. Vasc Health Risk Manag. 2006;2(3):277-283.

42. Jones MC, Patel M. Insulin detemir: a long-acting insulin product. Am J Health Syst Pharm. 2006;63(24):24662472.

43. Keating GM. Insulin detemir: a review of its use in the management of diabetes mellitus. Drugs. 2012;72(17):22552287.

44. King A. Advances in insulin therapy: a review of insulin degludec. J Fam Pract. 2012;61(5 Suppl):S28-31.

45. Rendell M. Insulin degludec: a long-acting modern insulin analogue with a predictable pharmacokinetic/pharmacodynamic profile. Drugs Today (Barc). 2013;49(6):387397.

46. Heinemann L, Beals JM, Malone J, Anderson J, Jacobson JG, Sinha V, Corrigan SM. Concentrated insulins: History and critical reappraisal. J Diabetes. 2019;11(4):292-300.

47. Woo V, Berard L, Roscoe R. Understanding the clinical profile of insulin degludec, the latest basal insulin approved for use in Canada: a narrative review. Diabetes Ther. 2020;11(11):2539-2553.

48. Heise T, Korsatko S, Nosek L, Coester HV, Deller S, Roepstorff C, Segel S, et al. Steady state is reached within 2-3 days of once-daily administration of degludec, a basal insulin with an ultralong duration of action. J Diabetes. 2016;8(1):132-138.

49. Lamb YN, Syed YY. LY2963016 Insulin Glargine: A Review in Type 1 and 2 Diabetes. BioDrugs. 2018;32(1):9198.

50. Bolli GB, Hahn AD, Schmidt R, Eisenblaetter T, Dahmen R, Heise T, Becker RH. Plasma exposure to insulin glargine and its metabolites M1 and M2 after subcutaneous injection of therapeutic and supratherapeutic doses of glargine in subjects with type 1 diabetes. Diabetes Care. 2012;35(12):2626-2630.

51. Lucidi P, Porcellati F, Candeloro P, Cioli P, Andreoli AM, Marzotti S, Schmidt R, et al. Glargine metabolism over $24 \mathrm{~h}$ following its subcutaneous injection in patients with type 2 diabetes mellitus: a dose-response study. Nutr Metab Cardiovasc Dis. 2014;24(7):709-716.

52. Clements JN, Threatt T, Ward E, Shealy KM. Clinical Pharmacokinetics and Pharmacodynamics of Insulin Glargine $300 \mathrm{U} / \mathrm{mL}$. Clin Pharmacokinet. 2017;56(5):449458.

53. Owens DR. Pharmacokinetics and pharmacodynamics of insulin glargine $300 \mathrm{U} / \mathrm{mL}$ in the treatment of diabetes and their clinical relevance. Expert Opin Drug Metab Toxicol. 2016;12(8):977-987.

54. Owens DR, Traylor L, Mullins P, Landgraf W. Patientlevel meta-analysis of efficacy and hypoglycaemia in people with type 2 diabetes initiating insulin glargine $100 \mathrm{U} / \mathrm{mL}$ or neutral protamine Hagedorn insulin analysed according to concomitant oral antidiabetes therapy. Diabetes Res Clin Pract. 2017;124:57-65.

55. Semlitsch T, Engler J, Siebenhofer A, Jeitler K, Berghold A, Horvath K. Ultra-)long-acting insulin analogues versus NPH insulin (human isophane insulin) for adults with type 2 diabetes mellitus. Cochrane Database Syst Rev. 2020;11:CD005613. 
56. Zhuang YG, Peng H, Huang F. A meta-analysis of clinical therapeutic effect of insulin glargine and insulin detemir for patients with type 2 diabetes mellitus. Eur Rev Med Pharmacol Sci. 2013;17(19):2566-2570.

57. Zhou W, Tao J, Zhou X, Chen H. Insulin Degludec, a Novel Ultra-Long-Acting Basal Insulin versus Insulin Glargine for the Management of Type 2 Diabetes: A Systematic Review and Meta-Analysis. Diabetes Ther. 2019;10(3):835-852.

58. Vargas-Uricoechea H, Frias JP. Efficacy and safety of the second generation basal insulin analogs in type 2 diabetes mellitus: A critical appraisal. Diabetes Metab Syndr. 2019;13(3):1975-1989.

59. Vargas-Uricoechea H. Efficacy and safety of insulin glargine $300 \mathrm{U} / \mathrm{mL}$ versus $100 \mathrm{U} / \mathrm{mL}$ in diabetes mellitus: a comprehensive review of the literature. J Diabetes Res. 2018;2018:2052101.

60. Rosenstock J, Cheng A, Ritzel R, Bosnyak Z, Devisme C, Cali AMG, Sieber J, et al. More similarities than differences testing insulin glargine $300 \mathrm{Units} / \mathrm{mL}$ versus insulin degludec 100 units/ml in insulin-naive type 2 diabetes: the randomized head-to-head BRIGHT trial. Diabetes Care. 2018;41(10):2147-2154.

61. Philis-Tsimikas A, Klonoff DC, Khunti K, Bajaj HS, Leiter LA, Hansen MV, Troelsen LN, et al. Risk of hypoglycaemia with insulin degludec versus insulin glargine U300 in insulin-treated patients with type 2 diabetes: the randomised, head-to-head CONCLUDE trial. Diabetologia. 2020;63(4):698-710.

62. Cernea S, Raz I. Insulin Therapy: Future Perspectives. Am J Ther. 2020;27(1):e121-e132.

63. Hong T, Lu J, Zhang P, Zhang Z, Xu Q, Li Y, Cui N, et al. Efficacy and Safety of Basal Analog Regimens in Type 2 Diabetes Mellitus: Systematic Review and Meta-Analysis of Randomized Controlled Trials. Diabetes Ther.
2019;10(3):1051-1066.

64. Lisco G, De Tullio A, Guastamacchia E, Triggiani V. Fixed-Ratio Combinations of Basal Insulin and GLP1RA in the Management of Type 2 Diabetes Mellitus: Highlights from the Literature. Endocr Metab Immune Disord Drug Targets. 2021;21(4):626-646.

65. Blonde L, Aschner P, Bailey C, Ji L, Leiter LA, Matthaei S, Global Partnership for Effective Diabetes M. Gaps and barriers in the control of blood glucose in people with type 2 diabetes. Diab Vasc Dis Res. 2017;14(3):172-183.

66. Reach G, Pechtner V, Gentilella R, Corcos A, Ceriello A. Clinical inertia and its impact on treatment intensification in people with type 2 diabetes mellitus. Diabetes Metab. 2017;43(6):501-511.

67. Khunti K, Gomes MB, Pocock S, Shestakova MV, Pintat S, Fenici P, Hammar N, et al. Therapeutic inertia in the treatment of hyperglycaemia in patients with type 2 diabetes: A systematic review. Diabetes Obes Metab. 2018;20(2):427-437.

68. Aschner P, Gagliardino JJ, Ilkova H, Lavalle F, Ramachandran A, Mbanya JC, Shestakova M, et al. Persistent poor glycaemic control in individuals with type 2 diabetes in developing countries: 12 years of real-world evidence of the International Diabetes Management Practices Study (IDMPS). Diabetologia. 2020;63(4):711-721.

69. Arthur B, Smith A, Bennett N, Bury D, Marshall B. PURL: NPH insulin: It remains a good option. J Fam Pract. 2020;69(2):94-95.

70. Wilson LM, Castle JR. Recent Advances in Insulin Therapy. Diabetes Technol Ther. 2020;22(12):929-936.

71. Cheng A, Bailey TS, Mauricio D, Roussel R. Insulin glargine $300 \mathrm{U} / \mathrm{mL}$ and insulin degludec: A review of the current evidence comparing these two second-generation basal insulin analogues. Diabetes Metab Res Rev. 2020;36(7):e3329. 